University at Buffalo School of Law

Digital Commons @ University at Buffalo School of Law

Contributions to Books

Faculty Scholarship

2016

\title{
The Regulatory Life of Threatened Species Lists
}

Irus Braverman

University at Buffalo School of Law, irusb@buffalo.edu

Follow this and additional works at: https://digitalcommons.law.buffalo.edu/book_sections

Part of the Anthropology Commons, Geography Commons, and the Law Commons

\section{Recommended Citation}

Irus Braverman, The Regulatory Life of Threatened Species Lists in Animals, Biopolitics, Law: Lively Legalities 19 (Irus Braverman, ed., Routledge 2016)

This is an Accepted Manuscript of a book chapter published by Routledge in Animals, Biopolitics, Law: Lively Legalities on 12/22/2015, available online: https://www.routledge.com/Animals-Biopolitics-Law-Lively-Legalities/ Braverman/p/book/9781138943117.

\section{C. ${ }_{\text {COPYRIGHT }}^{\text {N }}$}

This Book is brought to you for free and open access by the Faculty Scholarship at Digital Commons @ University at Buffalo School of Law. It has been accepted for inclusion in Contributions to Books by an authorized administrator of Digital Commons @ University at Buffalo School of Law. For more information, please contact lawscholar@buffalo.edu. 
Published in Irus Braverman (ed.). 2016. Animals, Biopolitics, Law: Lively Legalities (Routledge).

\section{Chapter 1}

\section{The Regulatory Life of Threatened Species Lists}

Irus Braverman

[A]nimals are divided into: (a) belonging to the Emperor, (b) embalmed, (c) tame, (d) sucking pigs, (e) sirens, (f) fabulous, (g) stray dogs, (h) included in the present classification, (i) frenzied, (j) innumerable, (k) drawn with a very fine camelhair brush, (1) et cetera, (m) having just broken the water pitcher, (n) that from a long way off look like flies.

---Michel Foucault, The Order of Things, quoting from Borges' "a 'certain Chinese encyclopedia"” (1970, xv).

It is with the whimsy and wonder of the above quote that Foucault begins his great expedition into the order of things. "Out of the laughter that shattered," Foucault says, "all the familiar landmarks of my thought_ — our thought, the thought that bears the stamp of our age and our geography_-breaking up all the ordered surfaces and all the planes with which we are accustomed to tame the wild profusion of existing things, and continuing long afterwards to disturb and threaten with collapse our age-old distinction between the Same and the Other" $(1970, x v)$. It is not incidental, I shall argue here, that Foucault began his study of order with the project of classifying nonhuman animals in the form of a list. The divide between the "human" and the "animal" is foundational for identifying, uniting, and distinguishing "us" from "them." As such, it provides the basis for the most fundamental classification of all — that between human and animal — and for the regulation of this classification through legal institutions.

The age-old capacity of lists to make and resist order has become a topic of renewed attention as of late. A growing literature on lists describes their power to create and organize 
global connectivities (Staeheli 2012, 234), emphasizing their role in security regimes in particular (Amoore 2011; Leyshon and Thrift 1999). What has been overlooked in this wave of renewed attention, however, is the important role of the list as a regulatory device for ordering human-nonhuman relations. This chapter will thus diverge from the anthropocentric focus of the existing literature on lists to explore the legal project of listing nonhuman species as "threatened" and "endangered." "All kinds of things become more interesting once we stop assuming that 'we' are the only place to begin and end our analysis," offer Hinchliffe and Bingham along these lines $(2008,1541)$. It is precisely toward such interesting valences around the seemingly technical and boring performance of the list that this chapter intends to direct attention. I will highlight the regulatory power of lists and their role in the grand project of ordering life: both human and nonhuman.

The last two decades have witnessed an explosion of national and global lists of threatened and endangered species (see, e.g., de Grammont and Cuarón 2006, 22). In 2010, at least 109 countries had produced a national red data book, national red list, or other national list of threatened species (Miller 2013, 198) and more than 25 listing systems of threatened species were used across North America only $(2013,192)$. The International Union of Conservation of Nature's (IUCN) Red List for Threatened Species ${ }^{\mathrm{TM}}$ (hereafter, the Red List) is the "mother" of all threatened species lists, the first and most comprehensive attempt at the global listing of all threatened species. For the last five decades, the Red List has provided "a map of how to do conservation," according to a prominent IUCN official (Lamoreux, interview).

Drawing on my previous work on the biopolitical dimensions of the Red List (2015a; 2015b), this chapter will explore the more and the less visible regulatory frameworks of listing threatened species through the Red List. Such explorations illuminate a number of common 
themes between human- and nonhuman-focused lists: visibility, translatability, comparability, inexhaustibility, simplicity, flexibility, credibility, objectivity, neutrality, technicality, and contagion. At the same time, these explorations also illuminate the differences between human and nonhuman lists: whereas various security lists (such as the secret drone "kill list," no-fly lists, and terrorist lists) identify humans who risk or threaten, threatened species lists typically identify nonhumans who are threatened.

The source of the difference between human- and nonhuman-focused lists is evident when examining them through a biopolitical lens: according to Foucault, only (certain) humans are privileged with political life. Animals and plants, along with all that is considered natural or wild, are relegated to the realm of biological life — namely, that which is killable. By contrast, this chapter applies the distinction between biological and political life also in the nonhuman context. Through their listing as threatened, certain species' lives are elevated to a political status, while the rest (initially, at least, the unlisted) remain biological, or mere, life (Braverman 2015c). In other words, whereas the rule for nonhumans is biological life and the threatened list is the exception, the situation is reversed in the case of humans, where the general rule is political life, and the list exceptionalizes and reduces such life to the biological realm.

Threatened species lists are thus both biopolitical and regulatory technologies: they (re)produce and reinforce underlying species ontologies by creating, calculating, and governing the boundary between the human and the nonhuman. Indeed, alongside their reinforcement of the biopolitical differentiation between various nonhuman species, threatened species lists also distinguish human from nonhuman species. Such a differentiated treatment of the life and death of nonhuman species through their en-listing, down- and up-listing, multi-listing, and un-listing translate into the positive protection and active governance of such species. Listing threatened 
species thus becomes a way to affirm — and justify — which lives are more and most important to save, thereby reifying the distinction between those who save (humans) and those who can only be saved (nonhumans).

Despite their significant differences, the bulk of this chapter will turn to examine several themes of the nonhuman list that are highly applicable in the context of the human list, too. This exploration will utilize an empirical and ethnographic methodology to illuminate characteristics of the list that travel across the human-nonhuman divide but that may not be as obvious or visible when observed only in the human context. I will start by introducing the list in general, and the Red List in particular, and will then proceed to examine the biopolitical aspects of the Red List as well as its global, regulatory, scientific, and seductive powers.

\section{The List}

The word "list" originates from border, edge, boundary (from Old High German lîsta; OED 2013), but it also means lust and desire, or inclination. Dating back to Old English from before the twelfth century, hlyst also means "to listen" (OED 2013). "List-making is frequently seen as one of the fundamental activities of advanced human society," offer Bowker and Star $(1994,188)$, while Goody (1977) suggests that the first written records to exist were lists of kings and equipment. Belknap adds along these lines: "Lists have been used for varied purposes throughout history. Among other things, they serve to enumerate, account, remind, memorialize, order. Lists abound in various sizes, shapes, and functions" $(2000,40)$.

A grocery list, kill lists, sex offender lists, and lists of threatened species - all are consecutive configurations of discrete items linked by a common goal that assigns them meaning and functionality. Lists name, classify, document, and simplify; they aspire to comprehensiveness, comparability, consistency, and uniformity, and are structured to delineate 
boundaries, produce authority, and promote visibility. Making a list is a way of making something apparent (or heard, recall hlyst) that is not otherwise so. Related to and drawing upon these functions, certain lists also standardize and regulate. Whereas all lists rely on various forms of classification, effectively "sorting things out" (Bowker and Star 1999)—some also prioritize. With such lists, not only the listed items but also their particular order is significant. Threatened species lists are a good example of this dual function. Such lists also typically share the following characteristics: they are a scientific method for highlighting those species under higher extinction risk with the explicit or implicit goal of focusing attention on conservation measures designed to protect them (Possingham et al. 2002, 503; emphasis added).

The Red List is by far the most influential and widely used method for evaluating global extinction risks. The IUCN has been producing red data books and red lists since 1963 (Lamoreux et al. 2003, 215). During the five decades of its use, the IUCN Red List of Threatened Species has evolved from a subjective expert-based system lacking standardized criteria to a uniform and global rule-based system (Miller 2013, 195; Mace et al. 2008). Despite (or as a result of) the insistence by many IUCN scientists on the Red List's non-prescriptive and apolitical character (Hoffmann, interview), it has had a profound influence on conservation laws and practices around the world (Possingham et al. 2002; Rodrigues et al. 2006). For instance, the Red List has inspired the development of numerous national and regional red lists and has functioned as an important source for the Convention on International Trade in Endangered Species of Wild Fauna and Flora (CITES) - a powerful international convention on trade that determines whether and how commercial trade in certain species will be regulated. Why does the Red List have such enormous normative power, and how does it work in the world? To answer these questions, I will first explore the biopolitical properties of the Red List. 


\section{The Biopolitical List}

Beyond their descriptive and declarative functions, threatened species lists normalize and regulate conservation and related actions; they also prescribe a series of material effects on very particular animal bodies (Braverman 2015a). While recognizing these functions and their effects on the individual level, the power of threatened species lists emanates from their capacity to order life at the level of the biological species — what Foucault refers to as biopolitics (Foucault 1990). Thinking and governing through species regimes, and through compiling lists of threatened species in particular, enables both an abstraction — a grid over the Linnaean kingdoms (Foucault, 1970)—and an embodiment: a personification of ecosystems, habitats, and populations. Since humans understand themselves primarily as an exceptional species and therefore both relate to, and differentiate themselves from, other species-it is important to critically examine the species lens and the work that it performs in the world.

For conservation scientists, the species is the foundational ontological unit through which life can be calculated and known (Braverman 2015c; Sandler 2012). Biermann and Mansfield reflect on the perspective of conservation experts that: "Managing individual nonhuman lives is meaningless in responding to the crisis of biodiversity loss; individual lives acquire meaning only when they advance the long-term well being of the broader population or are essential to sustaining key biological processes, especially evolution" $(2014,264)$. According to this way of thinking, the death of an individual gains meaning based on the level of endangerment of her or his species: once on the brink of extinction, the individual becomes larger than a singular life, and her or his death is therefore more than a singular death—it becomes the death of a life form, the death of nature (Braverman 2015c). Nonhuman life is measured numerically and valued according to its place in the scheme of the threatened list. 
At the same time, the deaths of so many other life forms who are not rare, charismatic, or visible enough to warrant the threatened designation fall outside the range of legal protections established by the list, or outside the list altogether. Such life forms are effectively "list-less": incalculable, unmemorable, and thus killable. Toward the end of this chapter, I argue that the conservation value of a species is defined through its inclusion and rank in an ever-proliferating number of lists and that the regulatory power of such lists is constantly eroded as new lists take their place in defining what is even more threatened, endangered, or extinct.

While much recent biopolitical work emphasizes thanatopolitics or necropolitics, this chapter brings into focus an affirmative biopolitics (Rutherford and Rutherford 2013, 426), namely "the ways in which biopolitics can be more about life than death, about inclusion rather than exclusion" (429). What happens to those listless lives that fall outside the realm of the threatened list does not configure into this account, which focuses instead on the viability of the listed. But such a focus on the affirmative does not entail a disavowal of death. Quite the contrary, "to make live does not mean to avoid death altogether but to manage death at the level of the population. In a biopolitical regime, death is transformed into a rate of mortality, which is open to intervention and management. This transformation erases the fact that not all life is equally promoted" (Biermann and Mansfield 2014, 259). I will discuss such erasures later, in the context of the scientific powers of the list.

\section{The Global List}

In its aspiration for a totalizing regime, the Red List illuminates the suitability of the list form for furthering global classification schemes. "The IUCN Red List assesses the status of species at a global level because this is the scale at which extinction occurs," explain Mace and other prominent figures in the Red List's construction (Mace et al. 2008, 1437). Lists are not 
only a way of channeling communication flows; they also "do the global" in their work as boundary objects that operate across time and space in an attempt at universal standardization.

The Red List "does the global" in a number of ways. First, it produces simple and visible chain-like links between otherwise loosely connected species, geographies, temporalities, and risks. "A global list deals with the global by adding, combining, and possibly ordering itemswithout the obligation to create a totalizing signifier of the global" (Staeheli 2012, 234). The use of species as the foundational unit of threatened lists - effectively rendering them the "currency of conservation" (Lamoreux, interview)—is not only ideological, as emphasized earlier, but also pragmatic. Species are the most common, visible, and easily measured unit for assessing the state of biodiversity. The Red List's visibility is an important factor in its global efficiency. Indeed, threatened species are "among the most visible and easily understood symbols of the rising tide of extinctions," making them an "emotive and politically powerful measurement of biodiversity loss" (Miller 2013, 192; see also Wilcove 2010).

In addition to utilizing species units, the Red List's visibility is enhanced through the list's color-coded visualization of danger (the red list) and its clear topology of endangerment, as well as through its adoption of "catastrophe-governance" that focuses on raising alarm by identifying and quantifying threats and extinction (Aradau and van Munster 2011, 85-106). John Lamoreux of the National Fish and Wildlife Foundation is a member of the IUCN and actively engaged in the red list assessments. He argues that "birders are famous for making lists: you have to be able to see what you saw. There's almost a listing mentality" (interview). Beyond these apparent functions, Lamoreux points out that the Red List is also important as a "rallying cry." "As an organization, you know what you stand for if you make a list of what's important," he tells me. The Red List, and threatened lists more generally, are thus a technology for the 
identification, differentiation, and visualization of certain forms of life with the goal of mobilizing universal support and political and legal action that aim to prevent (certain) nonhuman extinctions.

To serve as an effective technology for mobilization, the Red List must be easily translatable into various contexts—a "pan-linguistic device" (Staeheli 2012, 240). Red List Unit Programme Officer Rebecca Miller focuses on the broad functionality of lists as she writes: "The principle aim of a threatened species assessment is to estimate a species' risk of extinction in a comparable, repeatable, transparent, and objective manner" (Miller 2013, 191). The list's power as a global technology also lies in that it is both a plastic (Belknap 2000,35) and a homogenous register that promotes equality and comparability among species. The Red List is "applied to grasshoppers as well as blue whales," John Lamoreux tells me accordingly. "There's something about the applicability across all groups that's just truly amazing," he adds. By 2013, the IUCN Species Survival Commission network - the central scientific body of the IUCN that is comprised of thousands of scientists and experts from around the world — evaluated the global threat status of 71,576 species of animals, plants, and fungi (IUCN 2013c). The aim: to assess and appropriately categorize every living species on earth (ibid.).

This global scope of the Red List demonstrates how "[1]ists promise order as well as open-endedness, exhaustiveness as well as infinite addition" (de Goede forthcoming, 7). The generic list's "logic of infinite addition" (Staeheli 2012, 234) is an important element of the threatened species list as well and is exemplified to the extreme in the Red List context. Mike Hoffmann of IUCN's Species Survival Commission clarifies that the Red List is not just about registering threatened species, but about registering all species. "You can't talk about the status of biodiversity globally unless you've assessed everything," he tells me in an interview. A 2014 
Science article by Stuart Pimm and others illuminates the massive scale of this project. While an estimated 1.9 million animal species have been described and documented according to these authors, between 2 and 11 million animal species are still unknown. Some further argue that uncertainties in insect and fungi numbers make stating a plausible range for the number of unknown species impossible (Pimm et al. 2014, 987).

\section{The Regulatory List}

The Red List is especially powerful for its simplicity and comprehensiveness: "you want a category system that at the end of the day is relatively simple to implement," Hoffmann explains in an interview. The simplicity factor is intimately related to the aforementioned heightened comparability that the Red List affords. Generally, the assumption is that the simpler the categories and criteria, the more they can be applied across the board to regulate the various taxa on the list. Indeed, the criteria and categories "are designed to apply whether you are a mammal or a bird or a fungus or a plant or whatever you are" (Hoffmann, interview). For example, Criterion D requires a threshold of fewer than 50 mature individuals (IUCN 2001) - a number that applies to all taxa, from fungi to whales. Thus "one size fits all" approach can be quite problematic. The IUCN cautions, for example, that: "The choice of scale at which range is estimated may thus, itself, influence the outcome of Red List assessments and could be a source of inconsistency and bias. It is impossible to provide any strict but general rules for mapping taxa or habitats; the most appropriate scale will depend on the taxon in question, and the origin and comprehensiveness of the distribution data" (IUCN 2001).

Nonetheless, the central idea of the Red List "was to come up with one system that is applicable across all taxa, and you can therefore make comparisons across your different taxonomic groups" (Hoffmann, interview). In addition to its role in constructing a governable 
platform of comparability between different taxa, the Red List also provides comparability within particular taxa over time. It makes possible grand calculations such as this one: "On average, 52 species of mammals, birds, and amphibians move one category closer to extinction each year"; or this: "the deterioration for amphibians was equivalent to 662 amphibian species each moving one Red List category closer to extinction over the assessment period, the deteriorations for birds and mammals equate to 223 and 156 species, respectively, deteriorating at least one category" (Hoffmann et al. 2010, 1507; see, e.g., Figures 4 and 5). The capacity of the Red List to facilitate comparisons across previously disconnected units and fields corresponds with what has been described elsewhere as "a new mode of hyperconnectivity," whereby “[e]very item can now be combined with every other item" (Staeheli 2012, 240). The basic order of the list thus generates "a virtual space for recombinations, inventions, and narratives" (ibid.).

\section{Place Figure 4 here (IUCN 1)}

\section{Place Figure 5 here (IUCN 3)}

The Red List's regulatory powers lie also in its touted objectivity, transparency, and repeatability (namely, that if another expert were to conduct the assessment he or she would reach the same listing status; Brooks, interview). Nonetheless, it is not free from biases. According to Hoffmann, the biggest source of bias is when scientists want to list "their" species as threatened, "because they're worried that if it's not, they're not going to get money." The reverse also happens, with researchers who prefer that their species be listed as Least Concern "so that they can collect their species, put it in a specimen jar, and do research on it." "Our job," Hoffmann tells me, "is to be the neutral, objective, adjudicators of that process." IUCN's Standards and Petitions Subcommittee is the particular adjudicator in cases of disagreement over 
a Red List designation. According to Hoffmann, they are "the experts in the criteria, and what they say ... would essentially be considered gospel" (interview).

This brings me to consider the Red List's authority. Barney Long of the World Wildlife Fund and the IUCN tells me that "when you say this species is red listed by the IUCN as Critically Endangered, everyone automatically agrees and accepts that. There's no conversation, because the experts have agreed that it is Critically Endangered" (interview). These lists are so important, Long continues, because they are a means for conservationists to communicate with the public, and serve as a source of advice for policy makers on how to protect and manage species. The credibility of the list, it is inferred, creates a front behind which disparate conservation groups can unite, serving as a source of legitimacy, as a rallying cry, and also as a shared platform for regulatory controls. Today, the IUCN Red List is considered one of the most authoritative sources of information on the global conservation status of plants and animals (Lamoreux et al. 2003). Its influence has extended into numerous national and international regulatory systems. According to Miller, 76 countries use the IUCN methodology for their national red lists (Miller 2013, 197). Because of its effectiveness in governing the global efforts for saving threatened species the Red List has emerged as the central technology of modern conservation.

Then there are also the adverse and unintended effects of particular listings, which point to the unpredictability of governing across global and temporal scales. Brian Horne of the Wildlife Conservation Society tells me in an interview that collectors often "want the rare, and the unusual and different." Hence, when turtle breeders learned that a certain turtle species was soon to be listed under CITES' Appendix I, their prices for that animal increased dramatically: "[t]he turtle went from being a hundred dollar turtle to [costing] one thousand dollars" (see, e.g., 
Figure on page _, this volume). Another result is that once a species is downlisted (the term used to indicate that it has become less threatened), "you become a victim of your own success . . . because suddenly there's less funding sources available," which in turn translates into less protection (Bennett, interview). A final example of unintended consequences is that the price of black rhino horn on Korean markets increased by more than 400 percent within two years of their uplisting from CITES Appendix II to Appendix I, "which in turn coincided with a sharp increase in the poaching of black rhinos and in illegal trade in rhino horn" (Rivalan et al. 2007, 530; see, e.g., Figure on page __ this volume). The listing process produced by officials in one corner of the world has thus triggered responses in other corners of the world that have translated into the life or death of the relevant nonhuman animals.

\section{The Scientific List}

In addition to the simplicity, comparability, and translatability of threatened species lists, their global power, mobility, and ubiquity derive from their configuration as scientific, technical, and quantitative, and therefore as neutral and apolitical. According to the Guidelines for Appropriate Uses of IUCN Red List Data: “The IUCN Red List is developed through contributions from a network of thousands of scientific experts around the world. ... It uses a scientific process based upon objective criteria. Assessments are impartial, independent, and not politically driven.... The IUCN Red List is therefore a synthesis of the best available species knowledge from the top experts" (IUCN 2011). The insistence on the part of conservationists that the Red List is never political but only scientific exposes the underlying ideal "that science describes nature (and nature alone) and that politics is about social power (and social power alone)" (Bowker and Star 1999, 46). The list's visibility, accessibility, and transparency simultaneously serve to conceal its underlying political features and value-based judgments. 
In 1994, the IUCN revised its expert-based risk-ranking system into a data-driven quantitative system and finalized these categories and criteria in 2001 (IUCN 2014; Mace et al. 2008). To provide a global index of biodiversity and to identify those species most in need of conservation attention, IUCN scientists have stressed that "the classification system must be objective and transparent. It also needs to be applicable to a variety of species and habitats; standardized to yield consistent results independent of the assessor or the species being assessed; accessible to allow a variety of species experts to use it; scientifically defensible; and reasonably rigorous (i.e. it should be hard to classify species inappropriately)" (Mace et al. 2008, 1427). Another scientist writes that the current Red List is designed to provide "a standardized, consistent, and transparent method for assessing extinction risk, thereby increasing the objectivity and scientific credibility of the assessments" (Miller 2013, 195). Yet some scientists reject the Red List's claim of scientific objectivity. James Watson is president-elect of the Society of Conservation Biology and head of Climate Change Project at the World Conservation Society. He says about the rigid criteria of the Red List, and of threatened lists more generally, that "[a]t the end of the day, all listings are arbitrary: they're not driven by the laws of physics, they're actually created [ . . ] by humans trying their best to develop the most appropriate categories according to the best available knowledge" (interview).

Currently, the Red List classifies taxa into nine categories: Extinct (EX), Extinct in the Wild (EW), Critically Endangered (CE), Endangered (EN), Vulnerable (VU), Near Threatened (NT), Least Concern (LC), Data Deficient (DD), and Not Evaluated (NE) (IUCN 2014). The evaluation system consists of one set of criteria that are applicable to all threatened species (namely, those species within the categories of categories are Critically Endangered, Endangered, and Vulnerable) and that measure the symptoms of endangerment (but not the 
causes). Five criteria, listed A through E, are used to categorize taxa within these threatened categories. The criteria are: A) a reduction in population size; B) a small, reduced, fragmented, or fluctuating geographic range; C) a decline in size of an already small population; D) a very small or restricted population; and E) a quantitative analysis indicating the probability of extinction. To be listed as Critically Endangered, for example, a species must decline by 90 percent or more, cover less than $100 \mathrm{~km}^{2}$, or contain fewer than fifty mature individuals (IUCN 2014). A species need only satisfy one criterion to be listed. Although the other categories are included in the list's database, species classified within them are not assessed in the same manner as those within the threatened categories, hence being "less" listed.

Each of the categories contains a list of species, which can be traced in the Red List's online database, with one exception: the category of Not Evaluated (NE) contains no data. Mike Hoffmann explains: "NE just indicates that no attempt to evaluate the status of the taxon has been made. In reality, any species not on the Red List (i.e., more than 90 percent of species) is NE" (e-mail communication). A related concept is the "undescribed species." The IUCN Guidelines state that "The listing of undescribed species on the IUCN Red List is discouraged, but in exceptional circumstances these may be included" $(2014,5)$. Hoffmann explains: "Nearly all undescribed species are implicitly not evaluated, with a few rare exceptions when conditions outlined in the guidelines are met and an attempt has been made to evaluate the undescribed species against the categories and criteria." Generally, the further away from extinction the species is ranked, the less visible it is from the list's perspective — and the more "list-less" it becomes.

The Red List example demonstrates the close, if not inseparable, relationship between lists and databases, indeed "how the list may become a database" (de Goede forthcoming, 6). 
The Red List is one such hybrid database-list; it operates by translating analogous flows in risk levels and flexible forms of life into fixed digital categories. Easily distinguishable from one another, these categories serve as the basis for myriad regulatory actions. In this sense, the Red List is "a technique of government" (14). But whereas de Goede suggests that the list's "binary mode of in- and exclusion departs from risk based technologies of profiling and probability" (4), the Red List is an example of a sophisticated listing system that rests both on the binary of inclusion (of all known species) and exclusion (of the unknown) and on a differentiation among a set of distinct categories, determined by an algorithmic calculation of probability.

While the Red List's categories and criteria are "one size fits all," species are, by their very nature, diverse. To be listed, this diversity must be identified and measured. IUCN trainers guide assessors on how to interpret the categories and criteria across taxa so that they meet the thresholds. Hoffmann tells me about the assessors that, "[t]hey might be field biologists, taxonomists, academics, government personnel, park managers, or any one of a number of people." The process of figuring out whether a species meets the risk thresholds is complicated and not always clear-cut. Often, the final status depends on the tendencies of the particular assessors. According to Hoffmann, the central challenge facing the Red List's administration is that of assessors being either too evidentiary or too precautionary: "You either want perfect data, and therefore you are less likely to list something as threatened, so everything's going to go into Data Deficient—or you're very precautionary, you think everything's at risk, and so you throw it into a threatened category. Ideally, you want somewhere in the middle of those two things" (interview). Since scientists tend to be very evidentiary, Hoffmann continues, they often experience difficulty when working with the Red List, which is built "to give fuzzy numbers" (interview). 
"Not all threatened species are created equally," Hoffmann further explains in a statement that hints toward the actual impact of a Red List designation, what legal scholars often call "the law in action," in contrast to "the law [here, the list] on the books"- a distinction that rings true in other listing contexts as well, and especially with regard to kill and no-fly lists. Lamoreux explains, for example, that "even if you list a whole lot of dragonflies on the Red List, they're not going to suddenly get as much attention as a panda." He clarifies, accordingly, that "they're not all equal in the eyes of conservation funding or conservation action" (interview). Hoffmann is first to admit that "we have lots of biases," explaining that the system is "still very much biased towards vertebrates" and that "plants, fungi, and invertebrates are underrepresented" (interview).

Watson notes, similarly, that of 1,600 species on the Australian threatened list, only 35 percent receive government funding for conservation. "The things which get money are birds and mammals, and the things which don't get money are butterflies and plants," he tells me in an interview. Even the listing of a species as threatened, then, does not promise this species equal protection in relation to other listed species. Myriad criteria, as well as other more or less formal lists, determine which species are politically and legally defined as more or less worth saving. "We've got a long way to go," Hoffmann says about the current state of the Red List. Conservation biologist Arne Mooers adds that "the conservation biology community [itself] mistakenly considers probabilities of extinction as representing worth" (interview). For this reason, certain conservation biologists have been advocating for alternative or additional lists that would openly justify the de facto priorities adopted by countries, organizations, and institutions, thereby rendering them more scientific and transparent (Possingham et al. 2002). 
Alongside its reliance on fixed standards, the Red List also enables flexibility. Specifically, the number of species listed in each category changes every time it is updated—on the books, every five years. This is a result of various factors, including species being assessed for the first time, species being reassessed and moved into a different category of threat, and taxonomic revisions. The IUCN distinguishes genuine from non-genuine reasons (in other words, "real" from "technical" changes in threat levels that result from error, taxonomic revisions, or changes in threshold definitions) for revising a listing (IUCN 2013). The everchanging nature of the list makes it even more potent, as no protection, or un-protection, is never fixed or settled. Thus, scientists increasingly depend on the listing process.

This depiction of the Red List resonates with the general characterization of lists as inherently ambivalent in that "criteria for selection are not fixed at the outset, but evolve during the list's use" (Staeheli 2012, 237). Indeed, neither the manifold modifications in status nor the more radical changes in the overall criteria and its modes of calculation detract from the power of the Red List. Rather than a weakness, moreover, the Red List's shifting foundations in fact enhance its credibility; such changes also cannot be detected through a simple reading of the list. As Staeheli argues, "[r]eading a list does not reveal these myriads of small changes, struggles, and ambivalences ... the list looks perfect in itself, a homogenized and objectivized collection of cleanly separated items, in a space out of time" (ibid.). The decisions made in the course of the Red List's construction are therefore "forever lost to the historical record. . . In fact, their history is considered by most to be boring, trivial, and unworthy of investigation" (Bowker and Star 1999, 17).

\section{The Seductive List}

I have already explored the Red list's biopolitical, global, regulatory, and scientific 
properties. Lastly, I would like to explore the Red List's contagious, or seductive, qualities. It has already been acknowledged that lists produce an urge for more lists, highlighting "the contagious nature of list-making" (Staeheli 2012, 243), apparently classified by the manual of mental disorders (DSM) as "glazomania" (Cagen 2007; de Goede forthcoming, 8). The obsession with lists is nowhere more apparent than in the conservation context, where threatened lists and other priority lists for conservation proliferate by the day, alongside narratives on skyrocketing rates of extinction. Long explains that in addition to IUCN's Red List for species, priority lists are currently being developed by the IUCN for ecosystems and protected areas, essentially creating three separate lists within the IUCN alone.

More broadly, of the various threatened species lists, some "are designed purely to evaluate risk of extinction, whereas others focus on ranking species to receive priority conservation attention" (Miller 2013, 194). Accordingly, certain countries produce at minimum two separate lists, in order "to prevent blurring the line between extinction risk assessment, which is a scientific endeavor, and conservation priority setting, which is very much a valuebased judgment" (103). Such a dual existence of scientific versus political lists both constructs and reinforces the ostensibly apolitical nature of the scientific list alongside the social nature of the political one. Another challenge that arises in this context is intra-list incompatibility. Although the majority of conservation lists are referred to, generically, as threatened or endangered species lists, each list's definition of the level of threat that classifies a species as endangered or threatened can differ greatly from list to list. This has engendered quite a bit of confusion, not only on the part of conservationists but also on the part of policy makers and the public.

If the Red List focuses on identifying all threatened species from an ever-growing list of 
known species, other lists supplement this by identifying alternative targets for maintaining biodiversity. In this way, despite the terminological challenges, "lists intersect, feed each other, become consolidated, disseminated and translated" (de Goede forthcoming, 11). For example, the Alliance for Zero Extinction (AZE) aims to identify all sites around the globe that serve as the single remaining location for a species that is listed as Endangered or Critically Endangered under the IUCN Red List (AZE 2013). Of 20,934 of such species, the AZE has mapped 920 species in 588 sites, implying that these are the world's most threatened species (AZE 2013). Mike Hoffmann explains that, “These are the places where, if you don't do something here, now, for this species, you're going to lose a species" (interview).

Despite their common origin in and their immense drawing on the Red List, the various conservation lists differ in their perspective on what is most important about life and thus on what is most worth saving — whether rarity in numbers, unique territorial configurations, or evolutionary (phylogenetic) variation. Rather than a bifurcated understanding of life versus death, then, conservation lists parse the life of species into complex orderings according to their extinction risks, effectively establishing a gradation of animal bodies according to the perceived worthiness of their living and grieving. Even among those species who are deemed threatened, categories and criteria prioritize the ones who are perceived to be the most threatened of all: those whose lives are even more, and finally most, worth saving (Braverman 2015a; 2015b; 2015c).

Alongside the staggering proliferation of lists, a critique of existing listing processes as the exclusive metrics of conservation is currently emerging among scientists. In the words of James Watson of the World Conservation Society: "The conservation field is dominated by ecologists who really like to make lists." But "conservation is also not just about listing 
something," he continues, "it is about doing something." "This is not a failure of the list itself, it's the failure of the conservation community to develop other metrics beyond the list" (Watson, interview). Joseph et al. $(2009,328)$ argue along these lines that the existing listing approach in conservation typically "ignore[s] two crucial factors: the cost of management and the likelihood that the management will succeed" (Bottrill et al. 2011; Possingham et al. 2002; Walsh et al. 2012). Such critiques merely hint at the vast possibilities for problematizing, challenging, and "torquing" (Bowker and Star 1999, 27; 190) the politics of threatened species lists in ways that resist their authority and their seemingly automatic applications. "The trick is to question every apparently natural easiness in the world around us and look for the work involved in making it easy," suggest Bowker and Star $(1999,39)$.

\section{Conclusion}

Foucault contends that, "Order is at one and the same time, that which is given in things as their inner law, the hidden network that determines the way they confront one another, and also that which has no existence except in the grid created by a glance, an examination, a language; and it is only in the blank spaces of this grid that order manifests itself in depth as though already there, waiting in silence for the moment of its expression" (1970, xx). Listing a threatened species provides such a grid over the animal and plant kingdoms, giving particular forms of life a name, a number, a map, a database, and a threat rank—all establishing their "inner law" and uniqueness, and thereby elevating them from the listless abstraction of other, unknown, forms of life. The threatened species list is thus a biopolitical technology par excellence.

As part of its prominent biopolitical features, this chapter has illuminated the global, regulatory, scientific, and seductive dimensions of the threatened species list. Although my list of the list's dimensions is not exhaustive by any means, it nonetheless provides a sense of why the 
Red List and other threatened species lists carry such immense regulatory force in global conservation narratives. Conservationists typically believe that life —embodied in species unitsmust be assessed, calculated, and ranked if it is to be protected and saved. And while conservation is about saving life, it is also about sorting out and regulating which life should be privileged in this endeavor. Life that is worth conserving obtains meaning through an infinite calculus and through a proliferating number of lists.

\section{Interviews}

Bennett, Elizabeth. Vice President for Species Conservation, Wildlife Conservation Society. Onsite, New York City, NY, December 20, 2013.

Brooks, Tom. Head, Science and Knowledge Unit, IUCN. Skype, January 25, 2014.

Hoffmann, Michael. Senior Scientific Officer. Species Survival Commission, IUCN. Skype, January 9, 2014; e-mail communication June 26, 2015.

Horne, Brian. Turtle Conservation Coordinator, Wildlife Conservation Society. Skype, January 9, 2014.

Lamoreux, John. Biodiversity Analyst, National Fish and Wildlife Foundation. Telephone, January 7, 2014.

Long, Barney. Director, Species Protection and Asian Species Conservation, World Wildlife Fund. Skype, January 9, 2014.

Mooers, Arne. Professor of Conservation Biology, Simon Fraser University. Skype, January 6, 2014.

Watson, James. President-elect, Society of Conservation Biology; Head, Climate Change Program, the Wildlife Conservation Society (WCS), Skype, January 27, 2014.

\section{References}


Amoore, Louise. 2011. "Data Derivatives: On the Emergence of a Security Risk Calculus of Our Times." Theory, Culture and Society 28 (6): 24-43.

Aradau, Claudia and Rens van Munster. 2011. The Politics of Catastrophe: Genealogies of the Unknown. London: Routledge.

AZE. 2013. Alliance for Zero Extinction. http://www.zeroextinction.org/.

Belknap, Robert. 2000. “The Literary List: A Survey of Its Uses and Deployments.” Literary Imagination 2 (1): 35-54.

Biermann, Christine and Becky Mansfield. 2014. "Biodiversity, Purity, and Death: Conservation Biology as Biopolitics." Environment and Planning D: Society and Space 32: 257-273.

Bottrill, Madeleine, Jessica Walsh, James Watson, Liana Joseph et al. 2011. "Does Recovery Planning Improve the Status of Threatened Species?” Biological Conservation 144 (5): $1595-601$.

Bowker, Geoffrey \& Susan Leigh Star. 1999. Sorting Things Out: Classification and Its Consequences. Cambridge, MA: MIT Press.

----. 1994. "Knowledge And Infrastructure in International Information Management.” In Information Acumen: The Understanding and Use of Knowledge in Modern Business. Edited by Lisa Bud-Frierman, 187-213. London: Routledge.

Braverman, Irus. 2015a. "En-Listing Life: Red is the Color of Threatened Species Lists." In Critical Animal Geographies. Edited by Rosemarie Collard and Kathryn Gillespie, 184202. London, Routledge/Earthscan.

----. 2015b. "Is the Puerto Rican Parrot Worth Saving? The Biopolitics of Endangerment and Grievability.” In Economies of Death. Edited by Kathryn Gillespie and Patricia Lopez, 73-94. London: Routledge/Earthscan. 
----. 2015c. Wild Life: The Institution of Nature. Stanford: Stanford University Press.

Cagen, Sasha. 2007. To-Do List: From Buying Milk to Finding a Soul Mate, What Our Lists Reveal About Us. New York: Fireside.

Foucault, Michel. 1970. The Order of Things: An Archeology of the Human Sciences. New York: Vintage Books.

----. 1990. The History of Sexuality: An Introduction, Volume 1. New York: Vintage Books.

Goody, Jack. 1977. “What's in a List.” In The Domestication of the Savage Mind, 52-111. Cambridge: Cambridge University Press.

de Goede, Marieke. forthcoming, Environment and Planning D: Society and Space (full cite will be provided later).

de Grammont, Paloma and Alfredo Cuarón. 2006. “An Evaluation of Threatened Species Categorization Systems Used on the American Continent." Conservation Biology 20 (1): $14-27$.

Hinchliffe, Steve and Nick Bingham. 2008. "Securing Life: The Emerging Practices Of Biosecurity.” Environment and Planning A 40 (7): 1534-51.

Hoffmann, Michael, Craig Hilton-Taylor, Ariadne Angulo, Monika Böhm et al. 2010. "The Impact of Conservation on the Status of the World's Vertebrates." Science 330 (6010): $1503-9$.

IUCN. 2014. Guidelines for Using the IUCN Red List Categories and Criteria Version 11. http://jr.iucnredlist.org/documents/RedListGuidelines.pdf.

-----. 2013. IUCN Red List Summary Statistics. http://www.iucnredlist.org/about/summarystatistics.

-----. 2011. Guidelines for Appropriate Uses of IUCN Red List Data. 
http://www.iucnredlist.org/documents/RL_Guidelines_Data_Use.pdf.

-----. 2001. IUCN Red List Categories and Criteria Version 3.1. Gland, Switzerland and

Cambridge, United Kingdom: IUCN Species Survival Commission, IUCN.

Joseph, Liana, Richard Maloney and Hugh Possingham. 2009. “Optimal Allocation of Resources among Threatened Species: a Project Prioritization Protocol." Conservation Biology 23 (2): $328-38$.

Lamoreux, John, H. Resit Akçakaya, Leon Bennun, Nigel Collar et al. 2003. "Value of the IUCN Red List.” TRENDS in Ecology and Evolution 18 (5): 214-5.

Leyshon, Andrew, and Nigel Thrift. 1999. “'Lists Come Alive': Electronic Systems of Knowledge and the Rise of Credit Scoring in Retail Banking." Economy and Society 28 (3): 434-466.

Mace, Georgina, Nigel Collar, Kevin Gaston, Craig Hilton-Taylor et al. 2008. "Quantification of Extinction Risk: IUCN's System for Classifying Threatened Species." Conservation Biology 22 (6): 1424-42.

Miller, Rebecca. 2013. "Threatened Species: Classification Systems and Their Applications”, in Encyclopedia of Biodiversity 2nd edition. Volume 7. Edited by Simon Levin, 191-221. Waltham, MA: Academic Press.

OED Online. 2013. Oxford: Oxford University Press.

Pimm, Stuart, Clinton Jenkins, Robin Abell, Thomas Brooks et al. 2014. "The Biodiversity of Species and Their Rates of Extinction, Distribution, and Protection.” Science 344 (6187): 987-98.

Possingham, Hugh, Sandy Andelman, Mark Burgman, Rodrigo Medellín et al. 2002. "Limits to the Use of Threatened Species Lists.” Trends in Ecology \& Evolution 17 (11): 503-7. 
Rivalan, Phillipe, Virginie Delmas, Elena Angulo, Leigh Bull et al. 2007. "Can Bans Stimulate Wildlife Trade?" Nature 447 (31): 529-30.

Rodrigues, Ana, John Pilgrim, John Lamoreux , Michael Hoffmann et al. 2006. "The Value of the IUCN Red List for Conservation.” Trends in Ecology and Evolution, 21 (2): 71-6.

Rutherford, Stephanie and Paul Rutherford. 2013. "Geography and Biopolitics.” Geography Compass 7 (6): 423-34.

Sandler, Ronald. 2012. The Ethics of Species: An Introduction. Cambridge: Cambridge University Press.

Staeheli, Urs. 2012. "Listing the Global: Dis/Connectivity Beyond Representation?” Distinktion: Scandinavian Journal of Social Theory 13 (3): 233-46.

Walsh, Jessica, James Watson, Madeleine Bottrill, Liana Joseph \& Hugh Possingham. 2012. "Trends and Biases in the Listing and Recovery Planning for Threatened Species: An Australian Case Study.” Oryx 47 (1): 134-43.

Wilcove, David. 2010. “Endangered Species Management: The US Experience.” In Conservation Biology For All. Edited by Navjot Sodhi \& Paul Ehrlich, 220-35. Oxford: Oxford University Press. 